\title{
A CONSTRUÇÃO DE SINAIS-NOME PARA PERSONAGENS NA TRADUÇÃO DE LITERATURA INFANTO-JUVENIL PARA LIBRAS
}

\author{
CREATING PERSON-DENOTING NAME SIGNS \\ FOR THE CHARACTERS IN CHILDREN'S LITERATURE TRANSLATION TO \\ BRAZILIAN SIGN LANGUAGE - LIBRAS
}

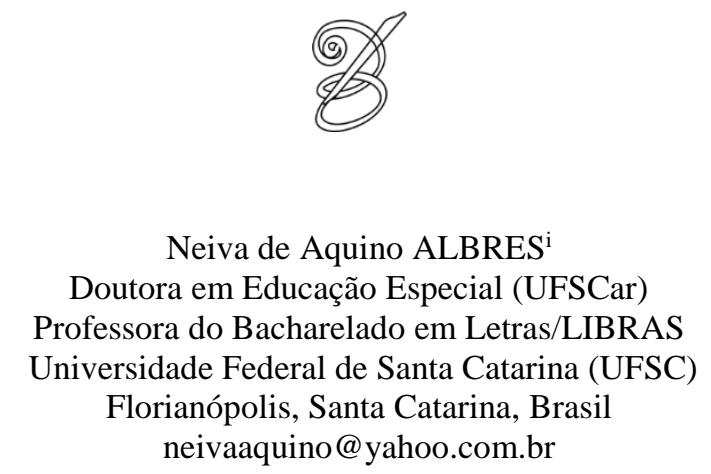

Resumo: Este artigo discute a tradução de nomes e a criação de sinais-nome pessoal. Segundo a revisão, há quatro categorias de sinais-nomes em Línguas de Sinais: (1) sinais-nome arbitrários (2) sinais-nome descritivos (3) sinaisnome inicializados e descritivos (híbrido) (4) sinais-nome emprestados. Nas traduções foram usados, principalmente, sinais descritivos e inicializados-descritivos na tradução dos livros analisados. Há diferentes formas de introduzir os personagens apresentando os seus nomes.

Palavras-chave: Tradução. Sinal-nome. Língua de sinais.

Abstract: This article discusses the translation of names and creating person-denoting name signs. According to the review, there are four personal name sign categories in Sign Language: (1) arbitrary name signs; (2) descriptive name signs; (3) initialized-descriptive name signs; (4) loan/borrowed name signs. Mostly there are using descriptive and initialized-descriptive personal name signs in the translation of the analyzed books. There are different ways to enter the characters presenting their names.

Key-words: Translation. Personal name signs. Sign language.

\section{Introdução}

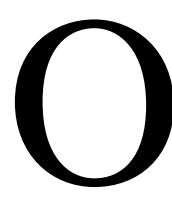

s surdos percebem o mundo por meio da visão e produzem a significação por meio de canais visuais de uma língua espacial. Neste contexto, convém destacar que os surdos apresentam uma forma visual-espacial para nomear e reconhecer as pessoas que os rodeiam. Enquanto que nas comunidades falantes de Português se usa o nome em Português, nas comunidades surdas, as pessoas recebem um sinal-nome criado a partir de normas construídas historicamente pelas comunidades surdas.

Segundo Aubert (1994) numa tradução, o tradutor deve adequar a técnica às expectativas, necessidades e possibilidades dos receptores finais. Cabe a ele expressar a mesma 
situação por meios estilísticos e estruturais diferentes, de forma a garantir a equivalência de expressões das línguas envolvidas (CAMPOS, 1986).

Buscando compreender como as comunidades surdas no mundo normatizam a criação desses sinais-nomes, apontamos a seguir algumas descrições sociolinguísticas (estudos) sobre esse fenômeno. As normas para se atribuir sinais-nome e os valores sociais particulares e práticas a eles associados variam consideravelmente entre diferentes línguas de sinais e culturas surdas em todo o mundo (McKEE e McKEE, 2000).

Para McKEE e McKEE (2000) nomes de pessoas, em qualquer cultura, são fenômenos que servem de informação sobre processos linguísticos e extralinguísticos (sobre as relações sociais, a identidade e a história). Em comunidades de surdos, em todo o mundo, os membros são comumente referidos por sinais-nome dados a eles por outras pessoas surdas em várias fases da vida, que são diferentes dos nomes legais de Registro Civil que partem da língua falada, nomes escolhidos pelos pais ao nascimento. Kourbetis e Hoffmeister (2002) acrescentam que sinais-nomes não são passados no seio das famílias, mas são atribuídos por membros da comunidade surda ou por colegas surdos no contexto educacional, quando os surdos não são 74 filhos de pais surdos. Uma vez que um sinal-nome foi atribuído permanece com o destinatário, geralmente, para a vida toda.

Todavia, há estudos (MINDESS, 1990) registrando práticas em que um sinal-nome é conferido e depois alterado, como também a possibilidade da evolução do sinal-nome sofrendo redução no sistema linguístico.

Meadow (1977) considera que o sinal-nome fornece grande fator identitário, chegou a essa conclusão ao entrevistar quatrocentos e cinquenta (450) pessoas de uma comunidade surda. A natureza dos sinais-nomes pessoais tem sido considerada como de uso em contexto informal, já que representa um segundo nome, esses sinais seriam como apelidos. Todavia, Paales (2009) considera os sinais-nome como oficiais, afirmando que no contexto da comunidade surda o uso dos sinais-nomes pessoais tem um estatuto oficial e são aplicados em situações formais.

O sinal-nome é dado depois de um período de conhecimento, esses sinais de nomes fazem parte da constituição da identidade de uma pessoa, o faz ser um membro reconhecido de uma comunidade de surdos (McKEE e McKEE, 2000).

Pessoas que participam da comunidade surda estão habituadas à co-existencia do nome e do sinal-nome. Esse é um fenômeno sóciolinguístico inerente ao universo das línguas de sinais, pelo contato de duas línguas com modalidades diferentes que requerem produções articulatórias distintas (orai-auditivas e gestuais-visuais). O nome próprio (de pessoas ou 
lugares) tem duas formas nas línguas de sinais: o nome oficial, dado por meio da soletração manual e o nome-sinal, que é um lexema singular que assume forma de apelido, geralmente de referênciação descritiva.

Os trabalhos que se atém às normas de construção articulatórias (características fonológicas) dos sinais-nomes revelam diferentes formas de produção desses sinais. Na Grécia, por exemplo, conforme Kourbetis e Hoffmeister (2002), a partir de entrevistas com 200 pessoas, afirmam que os surdos usam dois tipos de sinais-nomes, os descritivos e os arbitrários. A forma mais popular de nomeação é de sinais-nomes descritivos. Tradicionalmente, a maioria dos sinais-nome descrevem características pessoais. Os autores consideram que com a entrada de pessoas ouvintes na comunidade surda, sinais inicializados estão aparecendo, reflexo do contato das línguas de sinais e das línguas orais.

Sobre a relação de sinais entre pessoas ouvintes e surdas e suas possíveis diferenças, Paales (2009) investigou um grande número de sinais-nome de pessoas ouvintes em diferentes línguas de sinais (Língua Gestual da Estônia, Língua de Sinais Russa, Língua Gestual Finlandêsa e Língua de Sinais Alemã, entre outras), englobanco pessoas ouvintes como professores de escolas de surdos, intérpretes de língua de sinais, pesquisadores (linguístas), políticos, atletas, figuras religiosas e outras figuras públicas. Constatou que não há diferença linguística na formação de sinais-nome para surdos ou ouvintes, no entanto, há uma diferença na percepção do nome e na relevância desse sinal-nome para a construção identitária.

Na Estônia os sinais-nome podem ser atribuídos de quatro formas distintas: (1) sinaisnome arbitrários são criados com base na forma escrita do nome oficial da pessoa. Esse sinal contem as iniciais do nome e/ou sobrenome dado, representado por formas de mão. No Brasil, o sinal-nome arbitrário é chamado de sinal inicializado. (2) sinais-nome descritivos em que a formação de um sinal-nome metonímico é baseada na aparência da pessoa, comportamento, vestuário, peculiaridade, característica especial; (3) sinais-nome inicializados e descritivos (híbrido) em que a forma da mão, o que corresponde ao inicial do nome, é associada com algum atributo da pessoa de referência, tal como o penteado. Estes sinais-nome pessoais combinam dois elementos, as iniciais do nome oficial e a descrição; (4) sinais-nome emprestados de outra língua de sinais - empréstimo.

Paales (2010) considera que os sinais-nome descritivos e emprestados para sinais-nome são os principalmente empregados para pessoas surdas da Estônia. Na língua Americana de Sinais, Wilcox, Wilcox \& Jarque (2003) indicam ser mais comum o uso de sinais-nome 
descritivos, pela escolha de uma característica proeminente da pessoa, fazendo uso então da metonímia, do que os sinais-nome híbridos ou os tipo sinais-nome arbitrários.

Supalla (1990) argumenta que, embora ambos os sistemas forneçam sinais-nome para crianças surdas na Inglaterra, somente o sistema descritivo é nativo. A comunidade britânica de surdos tem uma história bem particular. Apesar de atualmente fazerem uso de sinais-nome descritivos, em primeiro lugar; sinais arbitrários e os derivados do Inglês também são usados, em menor proporção. A forma de atribuir sinais-nome variou ao longo do tempo, influenciado pela mudança de abordagem educacional. Há anos atrás os pais surdos não "batizavam" seus filhos-surdos ou ouvintes para além das formas de dedos soletrados de seus nomes em inglês, ou seja, pela soletração manual do nome da criança, sendo comum a criança adquirir sinaisnome descritivos fora de suas famílias (DAY, SUTTON-SPENCE, 2010).

No Brasil, essa temática foi pouco explorada. Freitas (2011) levantou cem (100) sinaisnome de surdos e ouvintes que fazem parte da comunidade linguística dos surdos em uma grande metrópole brasileira. Constatou que $51 \%$ são iniciados pelo alfabeto manual e descritivos (sinais-nome híbridos) e 49\% são icônicos a partir de características físicas (sinais76 nome descritivos). Não houve diferença significativa de classificação entre sinais de surdos e de ouvintes.

Na ficção, aos personagens de desenhos animados e de histórias infantis também são atribuídos sinais-nome pela comunidade surda. Aguilera (2008) afirma que "um nome significativo tem um papel na história, e não traduzi-lo é suprir parte da função para qual o mesmo foi criado". Personagens apresentam conceitos abstratos, apresentam uma identidade que deve ser transmitida na língua a ser traduzida. Esta opção pode ser compreendida como uma estratégia para manter questões culturais da comunidade de destino e, ao mesmo tempo, torná-lo mais compreensível à criança surda.

Pesquisadores têm indicado que para a tradução de literatura infanto-juvenil para a Libras é necessário fazer algumas adaptações, como também ocorre no processo de contação dessas histórias para as crianças surdas, já que o meio de expressão é a língua de modalidade gestual-visual (KARNOPP, 2010; MORAIS, 2010; MOURÃO, 2012). Dentre essas adaptações está a atribuição de um sinal-nome para os personagens.

Todas as personagens desse reconto possuem um nome visual, que é representativo para o espectador surdo/a. Provavelmente os nomes visuais atribuídos a cada personagem tenham origem na imagem do filme assistido pelos envolvidos na produção do objeto desta pesquisa. Não necessariamente todas as expressões faciais 
indicadas acima se apresentam nas personagens, tampouco se trata de pormenorizar cada uma [...] (MORAIS, 2010, p. 74).

A partir desses dados sociolinguísticos sobre a comunidade surda e da indicação de pesquisadores sobre adaptações no processo de tradução/contação de histórias para a Libras, interessa-nos estudar como os tradutores de Português/Libras atribuem e apresentam os sinaisnome das personagens dos livros traduzidos? Respeitando a que critério e quais as suas relações com a questão da autoria?

\section{Autoria, ética e estética e seus fundamentos em Bakhtin}

Bakhtin (1992) nos apresenta uma concepção de linguagem enunciativa, dialógica e ideologicamente marcada. Mas, o campo da tradução ainda é balizado pela pressuposição da autoria original, "a tradução não somente se desvia dessa intenção, como toma o lugar de outras: ela tem por objetivo direcionar-se a um público diferente ao atender as exigências de uma cultura e língua diferente" (VENUTI, 2002, p. 66).

A questão é que o tradutor precisa trabalhar nesse meio, entre o discurso de outrem e seu discurso. "A autoria, enquanto condição discursiva de intérpretes e tradutores, por vezes, pode levar esse profissional a considerar-se tão 'dono' daquilo que se traduz/interpreta que o discurso não passa mais a ser um discurso traduzido em que é possível encontrar marcas do enunciador da língua fonte [...]" (NASCIMENTO, 2012, p. 89).

Da mesma forma que na arte, a literatura é uma produção que reflete e refrata a ideologia. Para Bakhtin (2010a) para além da contemplação, a arte seria proposital, tendo só um propósito no acabamento estético, o que acontece por meio do Outro que dialoga com esse sujeito que se posiciona enquanto autor-criador dessa arte. O trabalho estético, por sua vez, está intimamente ligado ao caráter ético do trabalho do tradutor.

Pretende-se, neste texto, iniciar uma proposta de reflexão sobre a tradução produzida na esfera de literatura infanto-juvenil, sobretudo, acerca das possibilidades da tradução de histórias infanto-juvenis serem pensadas como uma realidade que é percebida e experienciada pelo tradutor, a qual, se constitui enquanto autor-criador dessa atividade.

Desse modo, em consonância com Bakhtin, aqui percebemos que o mundo do conhecimento e o mundo ético se unem de modo a resultar num ato estético do tradutor, pois, ao assumir uma posição autoral, o tradutor torna-se responsável pelo seu dizer em relação ao que diz e ao leitor em potencial (criança-surda). Aliado a isso, sob um dado enquadre, o tradutor, 
mergulhado em sua ideologia, organiza as vozes sociais que constituirão a arquitetônica de seu discurso na tradução.

Nesses termos, a reflexão sobre atividade estética apresenta-se importante, tendo em vista a relação constitutiva entre posição autoral e atividade estética. Essa atividade é criativa, é única e essencialmente marcada pela história de vida e subjetividade de cada sujeito (tradutor), sendo marcada ideologicamente.

Concebemos que a tradução é a materialização do ato estético, o que reflete um objeto estético. Assim como na arte, poderíamos pensar que o objeto final (tradução) deriva de um trabalho do tradutor que, na sua posição autoral, articula conteúdo, material e forma. O conteúdo são os conhecimentos que o tradutor seleciona e organiza - tendo em vista a provocação de uma atitude responsiva ativa como leitor do texto de partida, e o ato ético - a responsabilidade pelo seu dizer - "considerando que os enunciados que constituem o conteúdo são apenas "elos" de uma cadeia verbal mais ampla (dialogismo)" (BAKHTIN, 1992, p. 101).

Para compreender e dar sentido ao objeto estético, a literatura, é necessário que esse tradutor se desloque do lugar de um ser contemplativo e passe ao ser ativo, - torna-se um ser78 único-em-evento, que passa a compreender, baseado na significação dada ao objeto estético, perpassado pelos feixes de relações valorativas.

Partindo desses pressupostos, iniciamos uma descrição da produção discursiva, em especial, de livros de literatura infanto-juvenil bilíngues Português/Libras (em CD-ROM) referente ao sinal-nome dos personagens, com base nas reflexões promovidas por Bakhtin e o círculo.

Compreendemos o tradutor como um autor-criador e no ato tradutório revela a união do elemento ético e do cognitivo. Assim, no processo de tradução, o tradutor assume sua unicidade, como uma irrepetibilidade de seu posicionamento singular perante o mundo.

\section{Percurso metodológico}

Fundamentados teoricamente na abordagem histórico-cultural, especialmente nos pressupostos de Bakhtin (2010) e Vigotski (1998), que em essência compreendem o sujeito como um indivíduo singular e situado histórico e culturalmente - que na relação com o meio o transforma e é transformado por ele - este estudo, tem como foco de investigação a prática do tradutor de língua de sinais frente ao texto de literatura infanto-juvenil, bem como os aspectos de autoria envolvidos no processo de tradução de nomes-sinais das personagens.

Para a realização deste estudo foram levantadas as editoras produtoras de traduções de 
literatura infanto-juvenil para Libras e dentre elas selecionadas duas editoras, Editora Arara Azul e Brinque Book. Delas, selecionados quatro histórias traduzidas para a Libras, duas de cada editora. As histórias escolhidas foram: os clássicos infantis "As aventuras de Pinóquio" e "A História de Aladim e a Lâmpada Maravilhosa" da Arara Azul; "O homem que amava caixas" e "Guilherme Augusto Araujo Fernandes" da Brinque Book. Um dos critérios foi que os livros bilíngues Português/Libras tivessem sido traduzidos por equipes de tradutores experientes. Após a seleção dos materiais, os mesmos foram assistidos repetidamente para a realização do processo de descrição e análise.

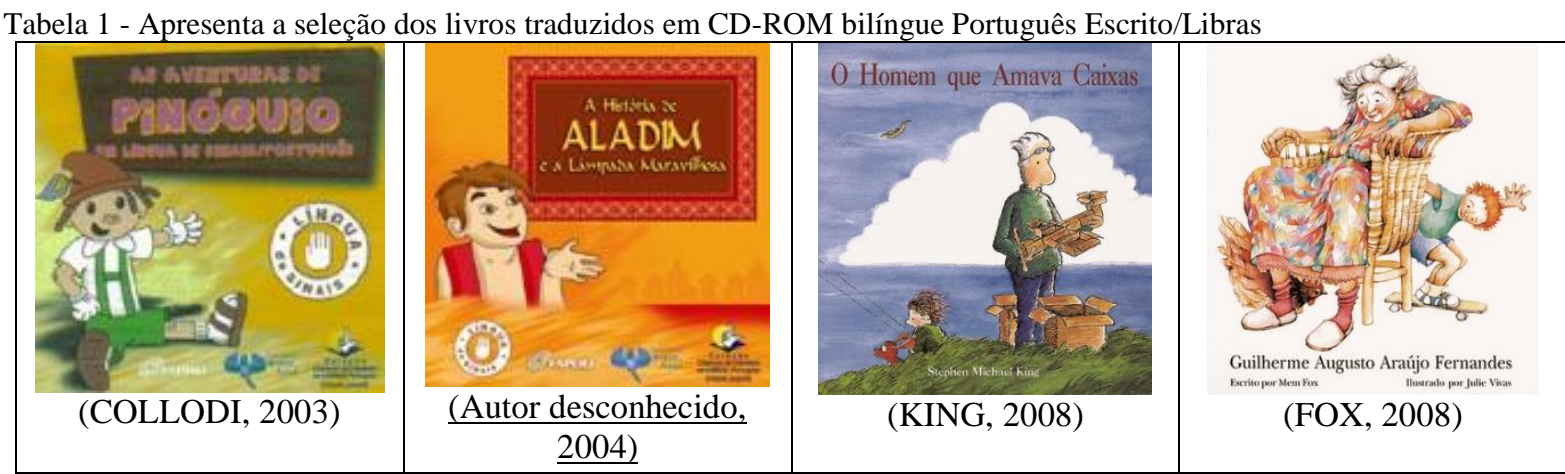

Fonte: Capa de todos os CDs

A partir das histórias traduzidas para a Libras, levantamos as personagens de cada história, descrevemos os critérios de atribuição dos sinais-nome pelos tradutores e as formas de apresentar esses sinais-nome.

\section{Análise das traduções de sinais-nome}

No universo da tradução, um dos aspectos de maior discussão tem se pautado no conceito de fidelidade. Os sujeitos produtores de traduções trabalham diretamente com sua autoria, com os sentidos singulares produzidos por suas leituras, devendo essa tradução assumir uma postura ética e responsável frente a certos atos, principalmente, quando se trata da tradução de livros. Isso porque, muitas vezes, quando produzem seus textos, alguns tradutores (sejam eles iniciantes ou mesmo especialistas) não refletem sobre o seu fazer, por vezes, desconsiderando as relações das línguas em contato. Assumimos a autoria do tradutor, aqui definida, como originalidade, essa autoria deve ser consciente e ética. 
Dentre os livros selecionados para análise, levantamos os nomes em Português das personagens, suas imagens e os sinais-nome atribuídos pelos tradutores. Desenvolvemos uma análise do critério estabelecido para criação do sinal-nome, conforme apresentado na tabela 1.

Tabela 2 - Apresenta o levantamento dos 27 nomes e sinais-nomes dos personagens

\begin{tabular}{|c|c|c|c|}
\hline $\begin{array}{l}\text { LIVROS E } \\
\text { TRADU- } \\
\text { TORES } \\
\end{array}$ & $\begin{array}{c}\text { NOME EM } \\
\text { PORTUGUÊS E } \\
\text { IMAGEM } \\
\end{array}$ & SINAL-NOME EM LIBRAS & $\begin{array}{c}\text { CRITÉRIO DE } \\
\text { ATRIBUIÇÃO DO } \\
\text { SINAL-NOME } \\
\end{array}$ \\
\hline \multirow{8}{*}{$\begin{array}{c}\text { As } \\
\text { Aventuras } \\
\text { de } \\
\text { Pinóquio } \\
\\
\text { Tradutor } \\
\text { para } \\
\text { LIBRAS: } \\
\text { Nelson } \\
\text { Pimenta e } \\
\text { Ana } \\
\text { Regina } \\
\text { Campello }\end{array}$} & Gepeto & $\mathrm{G}$ (no queixo) & Sinal-nome híbrido \\
\hline & Pinóquio & Nariz crescer & $\begin{array}{l}\text { Sinal-nome } \\
\text { descritivo }\end{array}$ \\
\hline & Strombóli & & $\begin{array}{c}\text { Sinal-nome } \\
\text { descritivo }\end{array}$ \\
\hline & Grilo Pepe & P-P-P para cima e para baixo & Sinal-nome híbrido \\
\hline & Raposa & & $\begin{array}{l}\text { Não tem sinal- } \\
\text { nome }\end{array}$ \\
\hline & Gata & & $\begin{array}{l}\text { Não tem sinal- } \\
\text { nome }\end{array}$ \\
\hline & $\begin{array}{c}3 \\
\text { Borboleta ou Fada }\end{array}$ & & $\begin{array}{l}\text { Não tem sinal- } \\
\text { nome }\end{array}$ \\
\hline & Baleia & & $\begin{array}{l}\text { Não tem sinal- } \\
\text { nome }\end{array}$ \\
\hline $\begin{array}{l}\text { A História } \\
\text { de Aladim e } \\
\text { a lâmpada }\end{array}$ & & & Sinal-nome híbrido \\
\hline
\end{tabular}

ALBRES. A construção de sinais-nome para personagens na tradução de literatura infanto-juvenil para libras Belas Infiéis, v. 5, n. 1, p. 73-92, 2016. 


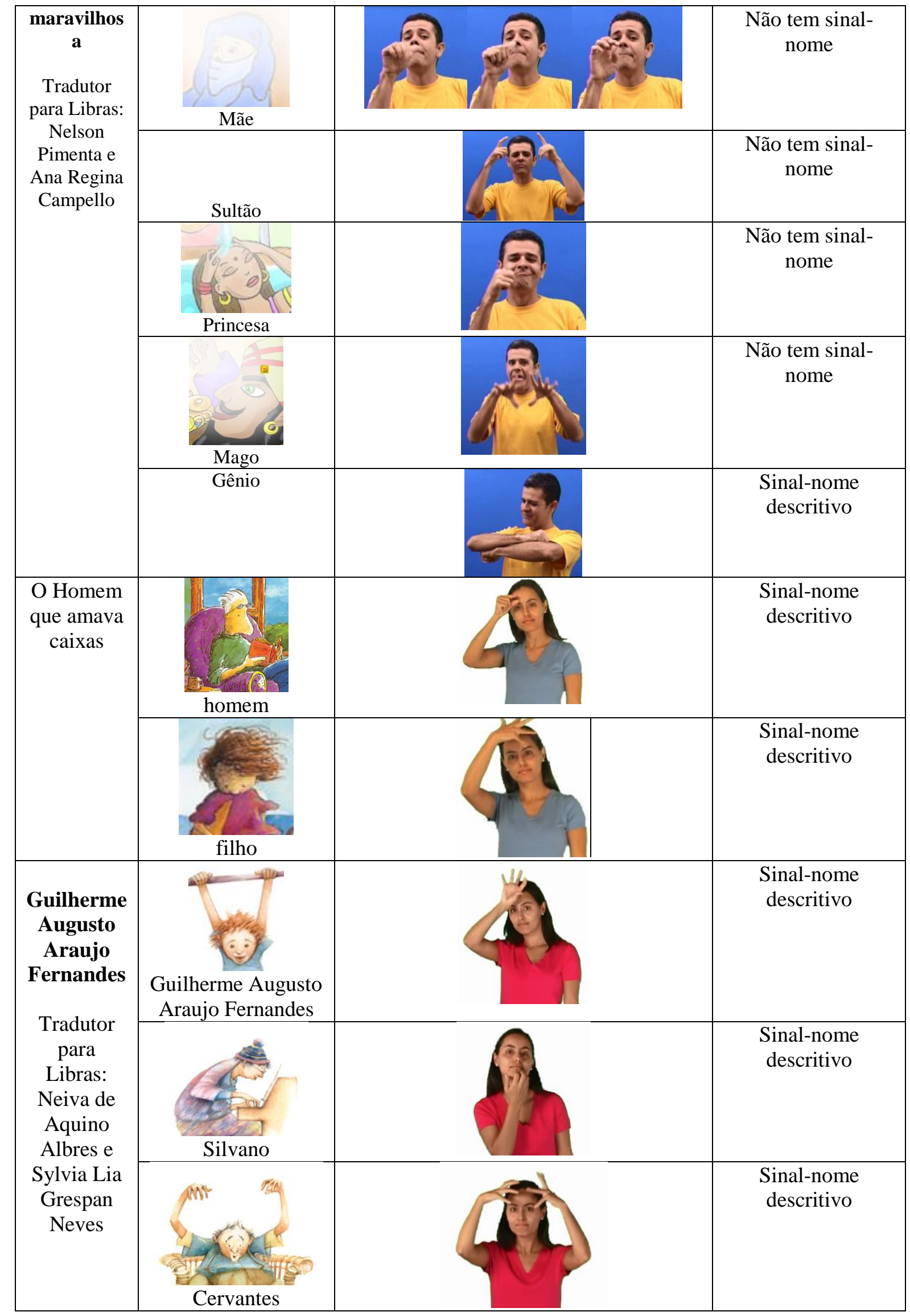




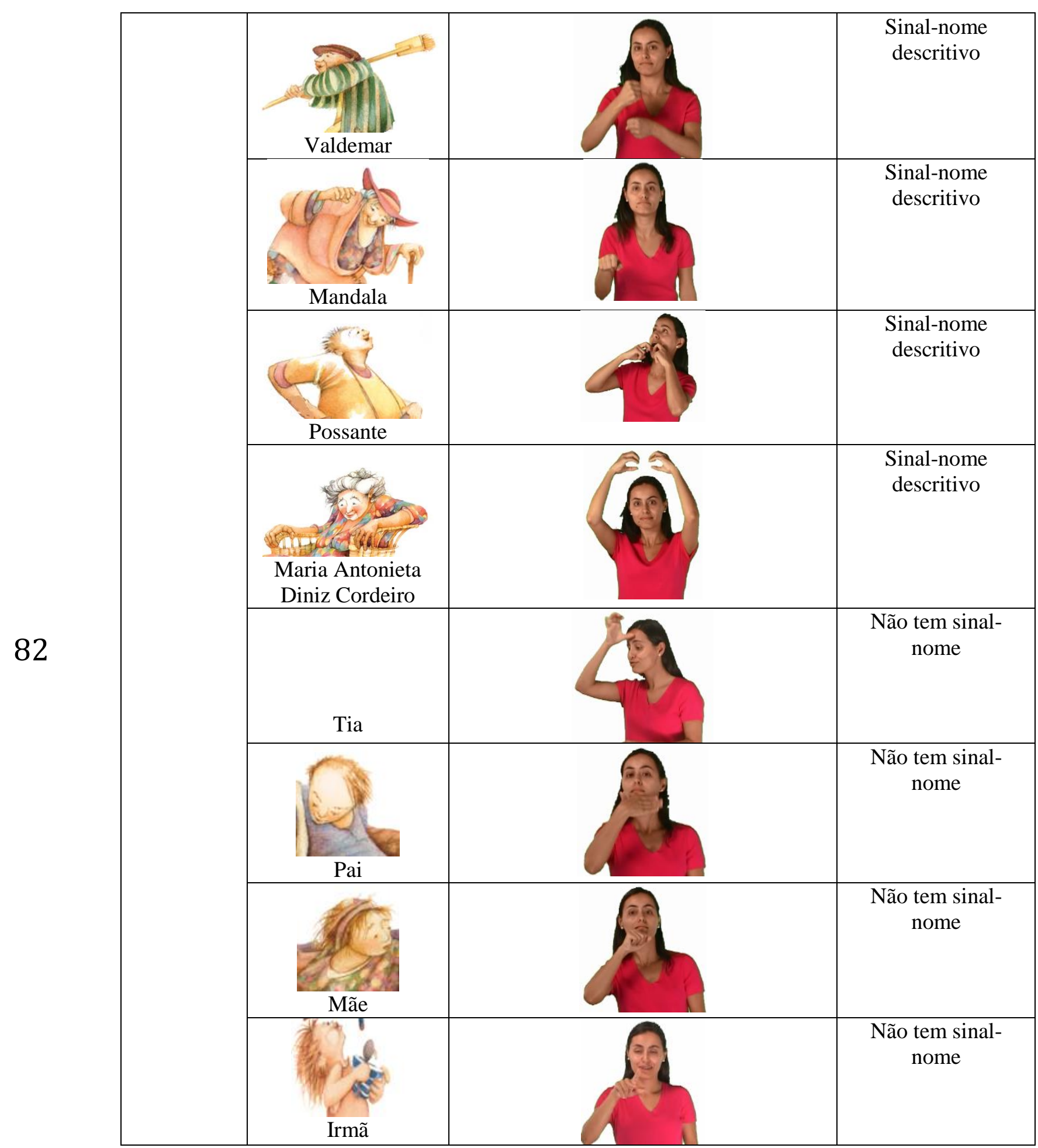

Fonte: Visualização do CD-ROM de Collodi, (2003), Autor desconhecido (2004), King (2008) e Fox (2008) por print-screen das páginas.

Organizamos a análise dos dados em duas categorias, a saber: a) Critérios de atribuição dos sinais-nome dos personagens, e b) Apresentando os sinais-nome dos personagens. 


\section{a) Critérios de atribuição dos sinais-nome das personagens.}

Como apresentado na introdução deste trabalho, os sinais-nome podem ser criados a partir de diferentes critérios: (1) sinais-nome arbitrários ou inicializados, (2) sinais-nome descritivos, (3) sinais-nome inicializados e descritivos (híbridos), e (4) sinais-nome emprestados.

Ao total foram vinte e sete (27) personagens, dentre estes, para doze (12) não foram atribuídos sinais-nome, visto que não eram personagens principais e muitos deles nem tinham nomes na história em Português, mas sim nomes comuns como: a mãe e a gata, por exemplo.

Nos livros em que personagens não têm nome oficial em Português, os tradutores fizeram opção por chamá-los de borboleta, fada, raposa, gata, pai, mãe, tia, etc.; sem lhes atribuir um sinal-nome específico. Apesar de no livro "O homem que amava caixas" os dois principais personagens não terem nomes oficiais e serem chamados de 'homem' e 'filho', as tradutoras optaram por dar um nome-sinal descritivo para cada um deles. Já que na comunidade surda, as pessoas e personagens têm sinais-nome, firmando uma perspectiva literária e estética. Considerando tal especificidade da comunidade alvo (público leitor - criança surda), as tradutoras criaram sinais a partir de características físicas das personagens.

Em ambos os casos, optou-se por acrescentar a explicação diluída no meio da sinalização, inserindo que este era o sinal da personagem, para situar o leitor, como uma forma de apresentação de que o homem tem 'este' sinal e o filho 'este' sinal.

Dentre as personagens a que são atribuídos sinais-nome (15 - 100\%), constatamos que da amostragem levantada, (12) 80\% dos sinais-nome são descritivos e (3) $20 \%$ dos sinais-nomes são híbridos (inicializados e descritivos). É recorrente o uso de sinais-nome descritivo, pela escolha de uma característica proeminente da personagem, fazendo uso então da metonímia, mais do que o uso de sinais-nome descritivos misturados ou os tipos arbitrários.

"Do ponto de vista dos objetivos extralinguísticos do enunciado todo, o linguístico é apenas um meio" (BAKHTIN, 2010, p. 313) constatado na tradução dos sinais-nome, visto que eles são construídos por meio da interferência de elementos verbo-visuais do livro impresso, que fornecem elementos para o projeto discursivo do tradutor como enunciador (autor) em Libras.

“A presença dos elementos verbo-visuais observados durante a interpretação da Libras indicam os efeitos de sentido instaurados a partir deles no processo de ressignificação entre línguas envolvidas nesse ato interpretativo" (NASCIMENTO, 2011, p. 112). 
Esse fato fica evidente quando além do elemento visual das características físicas ou psicológicas da personagem, o tradutor precisa trabalhar aspectos de rima no texto de partida de toda uma unidade de sentido, precisando rimar o nome da personagem com suas características, como nos casos do livro "Guilherme Augusto Araujo Fernandes":

Figura 1- Página do CD-ROM “Guilherme Augusto Araujo Fernandes”

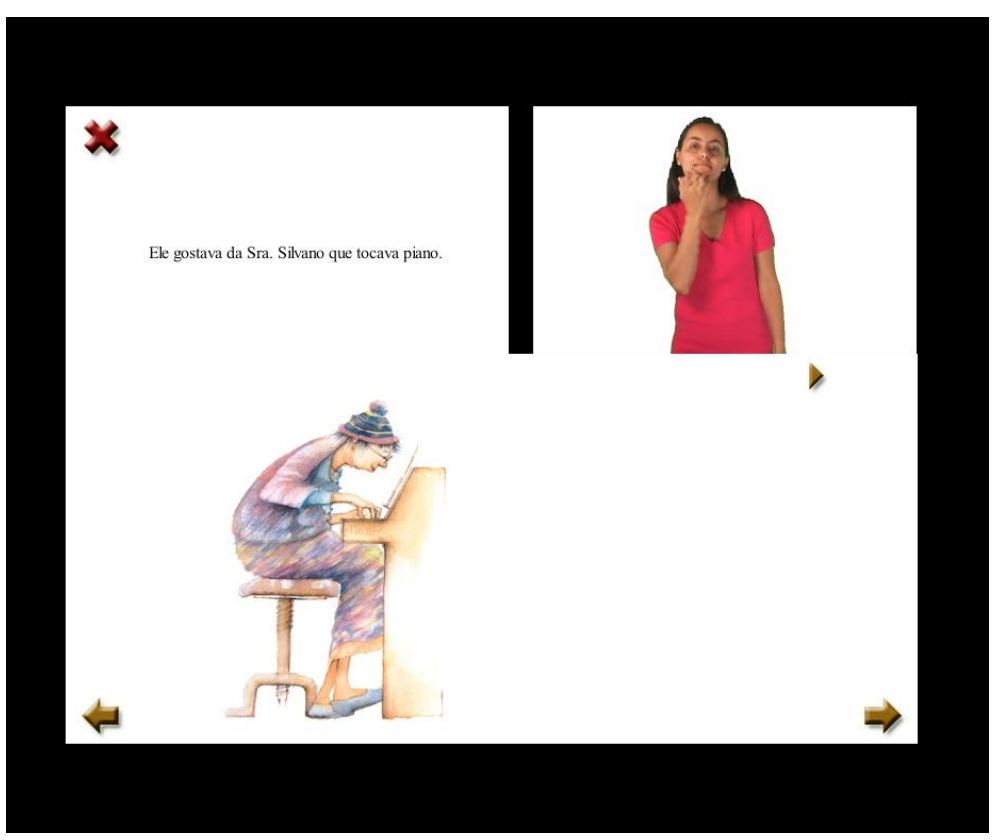

Fonte: Visualização do CD-ROM (FOX, 2008).

$\mathrm{Na}$ imagem 1, apresentamos a visualização do CD-ROM bilíngue Português Escrito/Libras. No texto de partida há o trecho "Silvano que tocava Piano", essa é a primeira vez em que aparece a personagem e é onde a tradutora apresenta seu nome e seu sinal-nome.

Quadro 1 - Sequência da sinalização apresentada na tradução (trecho 1)

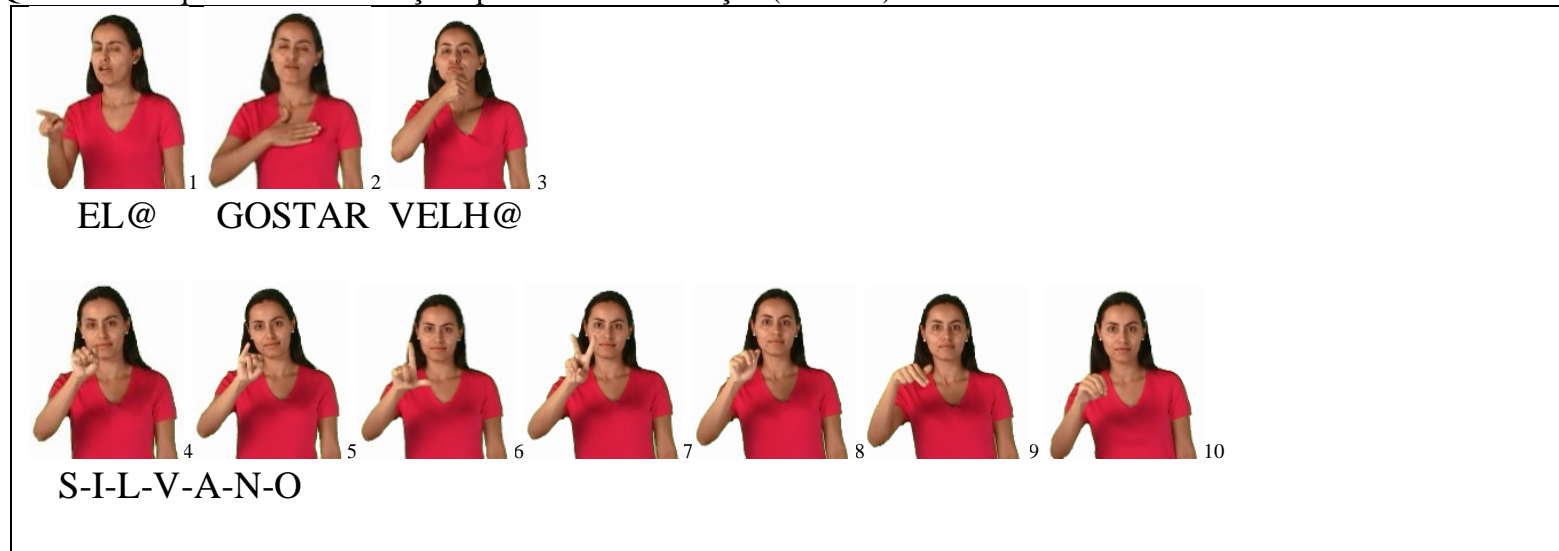

ALBRES. A construção de sinais-nome para personagens na tradução de literatura infanto-juvenil para libras Belas Infiéis, v. 5, n. 1, p. 73-92, 2016. 


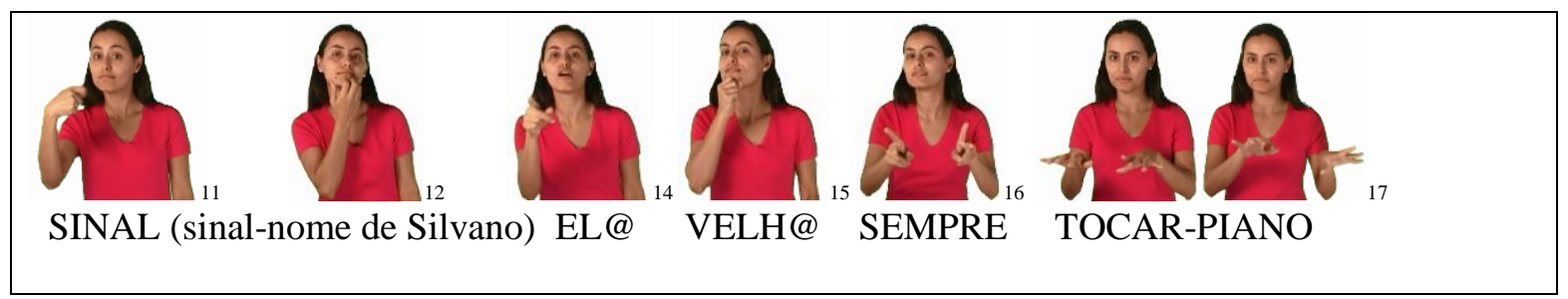

Fonte: Elaborada pela autora a partir do print-screen das páginas do CD-ROM.

A tradutora fez opção por criar um sinal também que "rimasse" com a característica da personagem, assim como no texto de partida. A característica da personagem é tocar piano, o sinal para piano é composto pelo dedilhar dos dedos. Dessa forma, no sinal-nome atribuído à Senhora Silvano usaram a mesma configuração e movimento dos dedos (construção articulatória - características fonológicas), mas sua produção foi desenvolvida no queixo, visto que a personagem tem um queixo retraído (Sinal 12 e sinal 17 do trecho 1).

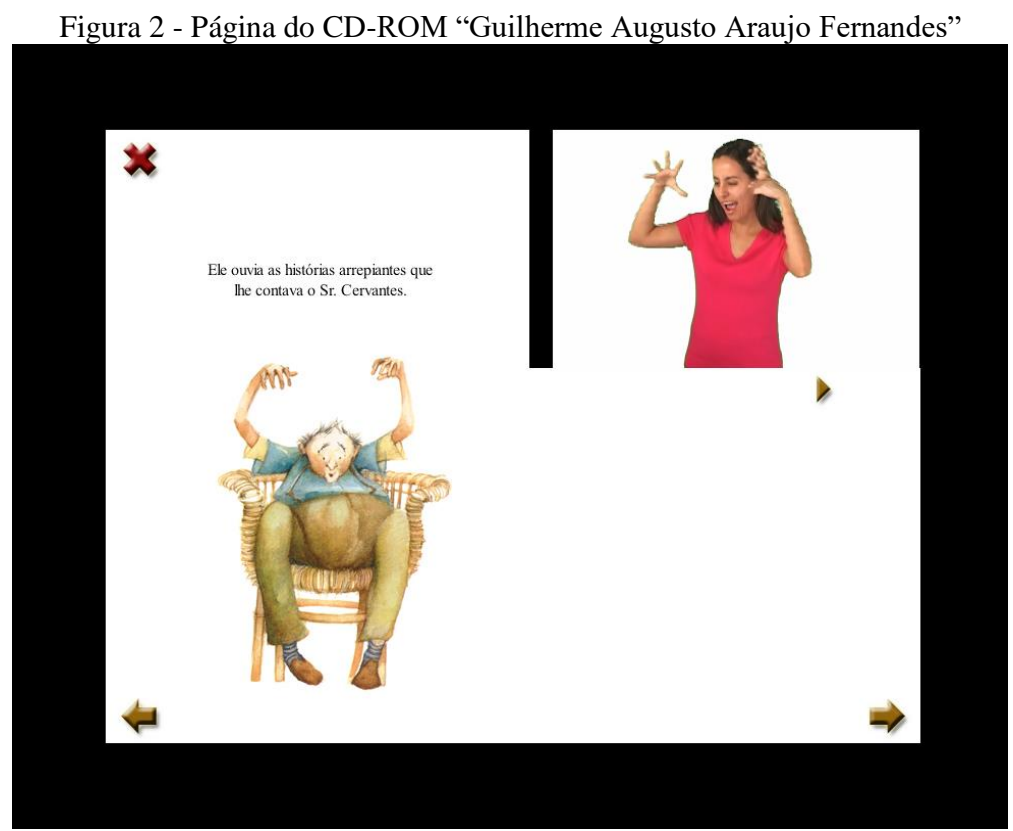

Fonte: Visualização do CD-ROM (FOX, 2008)

$\mathrm{Na}$ imagem 2, apresentamos a visualização do CD-ROM bilíngue Português Escrito/Libras. No texto de partida há o trecho "Histórias arrepiantes que lhe conta o Sr. Cervantes". 
Quadro 2 - Sequência da sinalização apresentada na tradução (trecho 2)

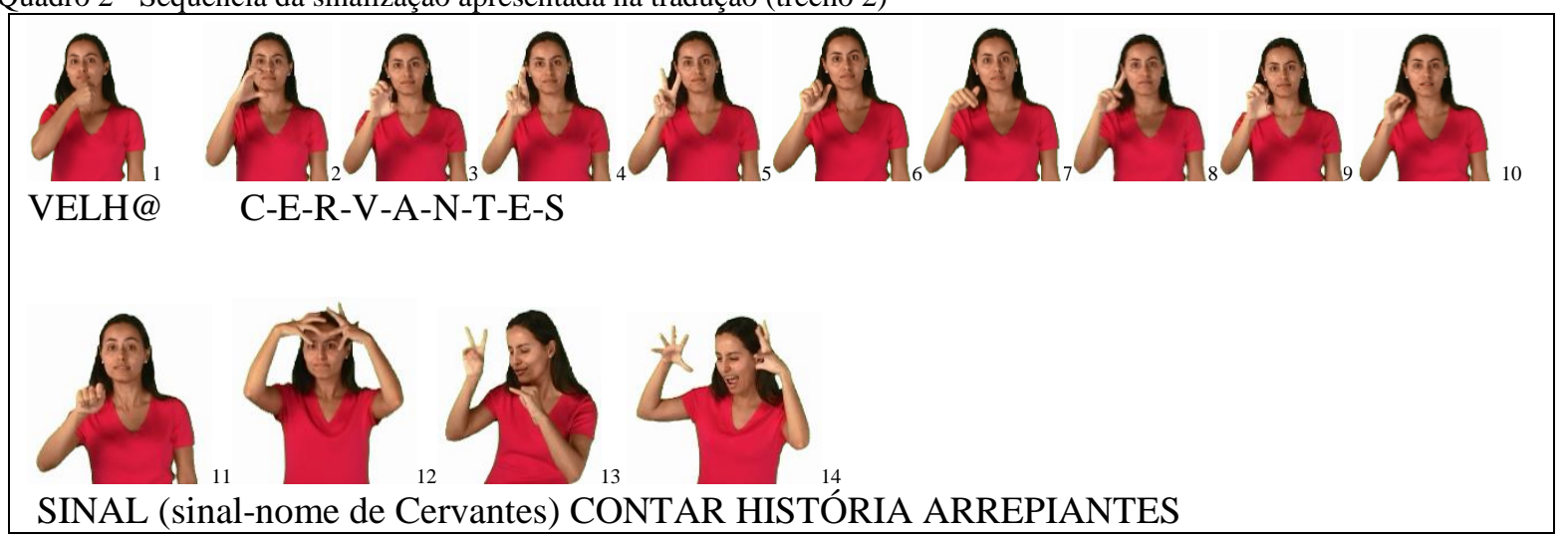

Fonte: Elaborada pela autora a partir do print-screen das páginas do CD- ROM.

Na mesma tentativa, a tradutora criou o sinal de Cervantes descrevendo seus poucos cabelos arrepiados para frente, aproximando a articulação do sinal-nome com a característica das histórias que o senhor contava (histórias arrepiantes), fazendo uso do sinal de aterrorizar e expressão facial de abocanhar simultaneamente, de similar produção fonológica ao sinal de Cervantes. A intenção foi de dar ao leitor a possibilidade de construir sentido estético o mais próximo do pretendido efeito do autor do texto de partida (sinal 12 e sinal 14 do trecho 2).

O/a espectador/a surdo/a desempenha a leitura da imagem poética em uma moldura a tela de um aparelho eletrônico. O prazer de ler as palavras sinalizadas acompanhadas das expressões faciais e corporais e o enlevo da leitura da imagem associam-se ao desejo de não interrompê-la. (MORAIS, 2010, p. 93).

O gênero literatura infanto-juvenil, em sua totalidade verbo-visual, evidencia o quanto o tradutor trabalhou com os elementos da literatura e das imagens do livro, dos detalhes das características físicas dos personagens, construindo enunciados próprios a fim de provocar no leitor (criança-surda) a construção de sentido estético da obra traduzida.

Parece-nos razoável pensar que, na tradução, a atividade estética seria realizada pelo tradutor que assume uma posição autoral a partir da experienciação e reflexão sobre essa experienciação concreta (leitura da história em Português e visualização das imagens do livro). Ao promover a união do conhecimento e do ato ético - que criam a natureza e a humanidade social - esse tradutor, por meio do ato estético (resultante dessa união), "evoca essa realidade preexistente do conhecimento e do ato [...] enriquece-as e completa-as" (BAKHTIN, 2010b, p. 33). Logo, o ato estético que tem por finalidade a construção do objeto discursivo (a narrativa da história), também cria uma unidade entre o mundo do conhecimento e o mundo ético. 
Aspectos enunciativo-discursivos que circulam na literatura infanto-juvenil colaboram para a produção articulatória (características fonológicas) elaborada pelo tradutor, a partir de uma reflexão de elementos verbo-visuais. A leitura atenta ao material (livro) contribui para que o tradutor elabore suas estratégias interpretativas, devendo ser ética e estética.

\section{b) Apresentando os sinais-nome das personagens}

Dentre as possibilidades de indicação de sinal-nome, constamos ser recorrente sua apresentação logo após a soletração do nome oficial da personagem, como indicado nos trechos 3, 4, 5, 6 e 7. Todavia, há especificidades nas formas linguísticas de apresentação do sinalnome.

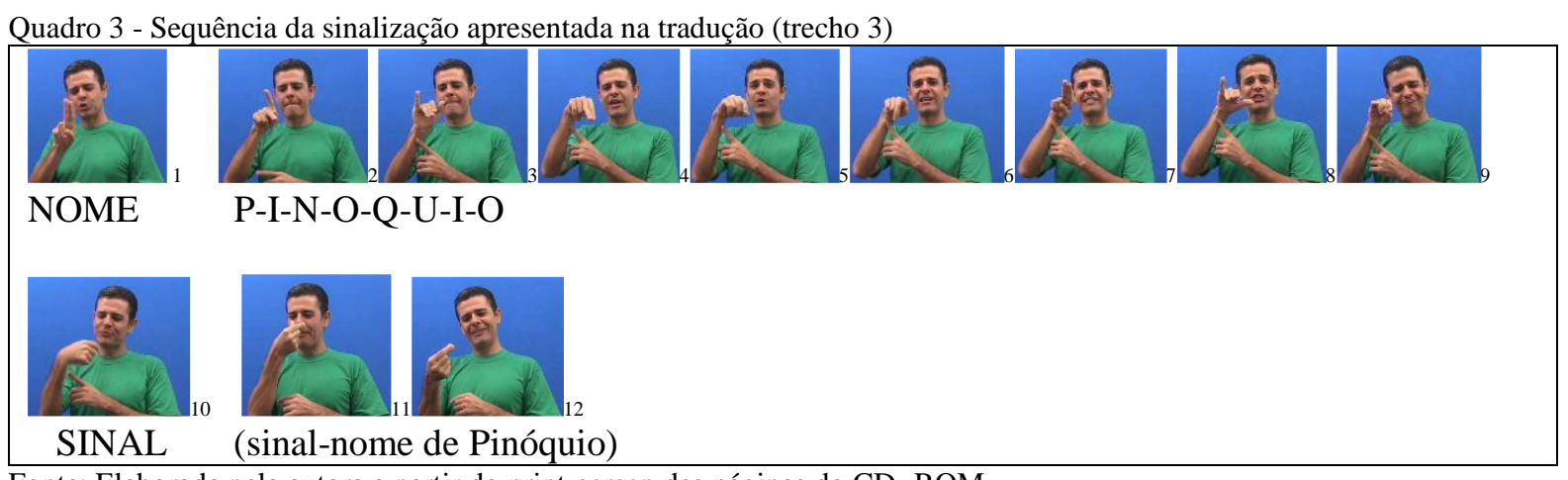

No trecho 3, o tradutor utilizou a datilologia do nome P-I-N-O-Q-U-I-O com a mão direita ao mesmo tempo em que utilizou a outra mão como "indicativo-apontação" (mão de base) e ao final da soletração produz o sinal SINAL com a mão usada para soletração, nos possibilitando a construção da significação como "seu sinal". Refere-se a uma situação em que as duas mãos trabalham simultaneamente na produção da significação, desvinculada dessa enunciação concreta não teria o mesmo sentido. Ao final, o tradutor atribui o sinal ao personagem (nariz comprido), retratando um fato próprio da comunidade surda, o de dar um sinal-nome para as pessoas.

Quadro 4- Sequência da sinalização apresentada na tradução (trecho 4)
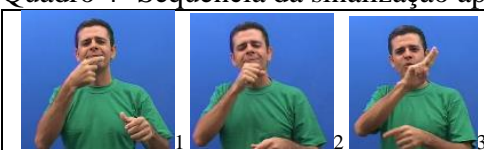

HOMEM VELH@ NOME
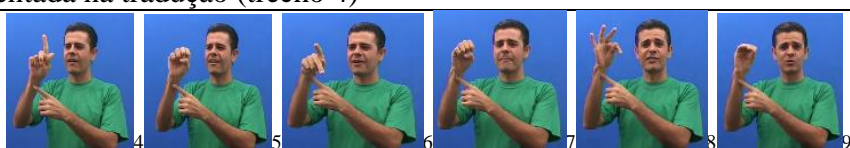

G-E-P-E-T-O 


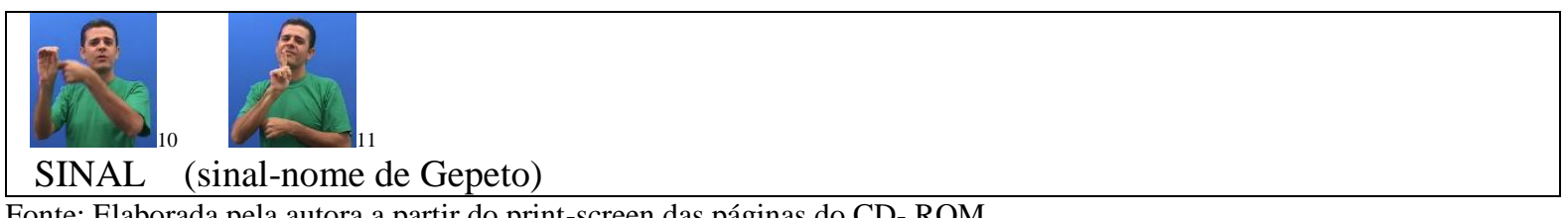

Fonte: Elaborada pela autora a partir do print-screen das páginas do CD- ROM.

No trecho 4, o tradutor faz uso da mesma sequência nome + datilologia "seu sinal" + sinal-nome. Contudo, a mão de base é utilizada como "indicativo-apontação". Desta vez é ela que faz a função de apresentar o sinal da personagem.

Assim, identificamos duas formas distintas para se apresentar o sinal do personagem: Podemos verificar melhor esse fenômeno no sinal 10 do trecho 3 e do trecho 4, respectivamente ilustrados por 10 (trecho 3) e 10 (trecho 4).

A alteração da mão que indica o sinal da personagem não altera o significado pretendido, mas revela diferentes possibilidades do tradutor apresentar o sinal-nome.

No processo de apresentação, o tradutor faz acréscimos, pois a informação que Gepeto era velhinho não consta do texto de partida em Português. Na tradução, ela diz HOMEM VELH@ (imagens 1 e 2 do trecho 3). Considerando que o gênero discursivo é uma narrativa e a história se refere à vida de idosos, o sinal HOMEM VELH@ cria uma conectividade com a história em desenvolvimento.

Quadro 5 - Sequência da sinalização apresentada na tradução (trecho 5)

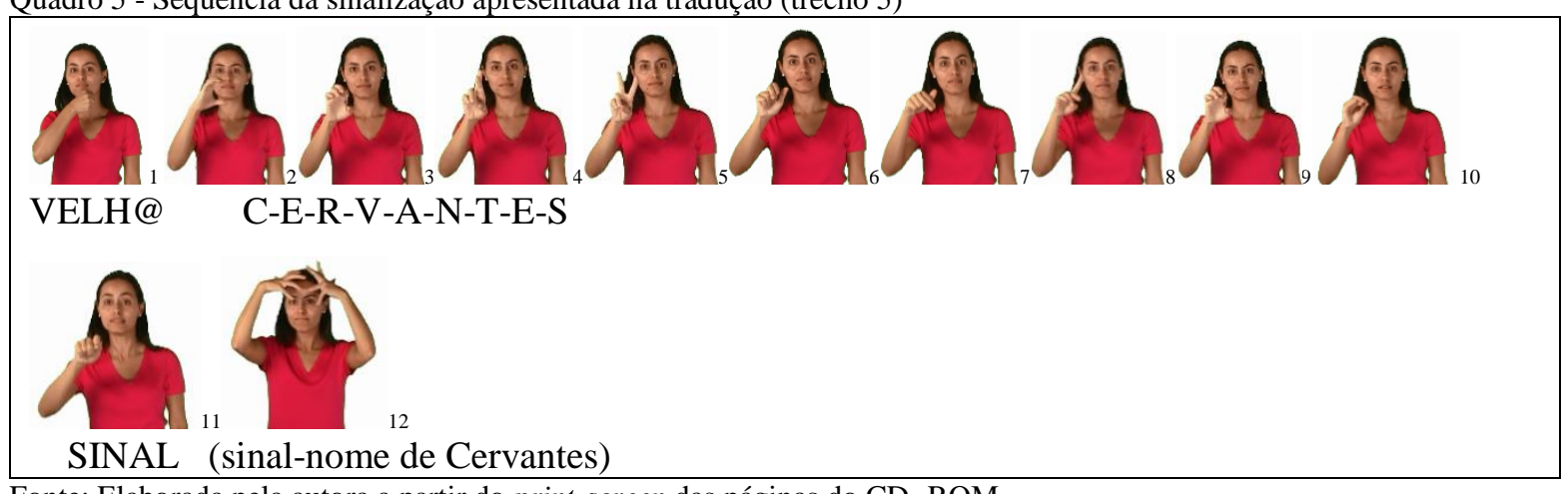

Fonte: Elaborada pela autora a partir do print-screen das páginas do CD- ROM.

No trecho 5, a tradutora utiliza a sequência de soletração do nome (datilologia) + "seu sinal" + sinal-nome. Porém, não há a mão de apoio, toda essa sequência é feita apenas com uma mão, a questão da espacialidade foi respeitada quando a tradutora usa o termo SINAL (imagem 11 - trecho 5) no mesmo ponto espacial de referência em que soletrou o nome da personagem. 


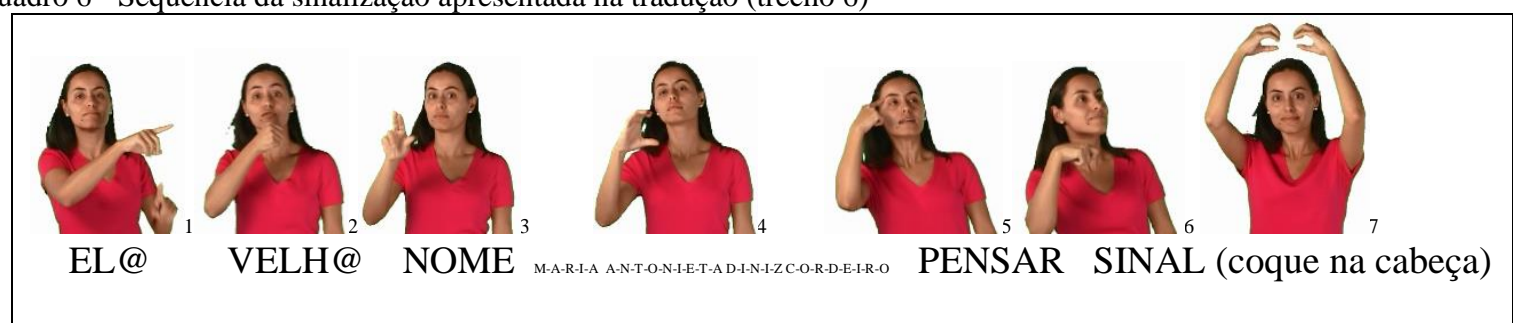

Fonte: Elaborada pela autora a partir do print-screen das páginas do CD- ROM.

Outra possibilidade identificada, em nossos dados, foi a sequência: soletração do nome $($ datilologia $)+$ pensar + "seu sinal" + sinal-nome. No trecho 6, a tradutora indica que esse sinalnome foi pensado. Antes a esse trecho da história, a tradutora expressa que dentre os velhos do asilo a dona Maria Antonieta Diniz Cordeiro é a velhinha que ele mais gosta, pois os dois têm quatro nomes e poderiam trocar segredos, como estava no texto de partida. Da forma como foi sinalizado indica que o personagem Guilherme (menino) que deu o sinal para a senhora.

Quadro 7 - Sequência da sinalização apresentada na tradução (trecho 7)

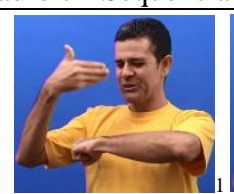

EU-SOU

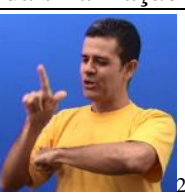

G-E-N-I--O
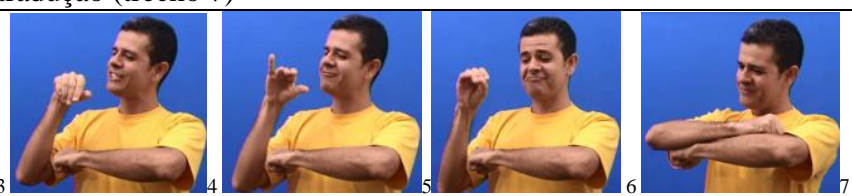

(sinal-nome do Gênio)

Fonte: Elaborada pela autora a partir do print-screen das páginas do CD- ROM.

Há possibilidade também do tradutor assumir a primeira pessoa e apresentar-se como se fosse a personagem, assim como foi feito no trecho 7. EU-SOU+ nome (datilologia) + sinalnome. De tal modo, simultaneamente a um processo de incorporação o tradutor apresenta o sinal-nome da personagem.

Constatamos que todos os tradutores atribuíram sinais-nome às personagens, e as formas de apresentá-los é juntando o nome oficial em Português e o sinal-nome em Libras para a identificação na comunidade surda.

A "virada cultural" que contribuiu para a mudança radical do paradigma da homogeneização cultural desencadeou o entendimento da diferença cultural e das relações de poder, possibilitando a interpretação da cultura sob outro olhar, ou seja, não há uma única cultura e sim culturas. $\mathrm{O}$ entendimento da multiplicidade cultural permitiu a desconstrução do conceito homogêneo, único e determinante de cultura e de identidade. Nesse sentido, a literatura produzida na língua de sinais, a partir do caráter híbrido das sociedades, precisa incentivar a convivência com a diferença (MORAIS, 2010, p. 138). 
O que por muitos anos foi considerado irrelevante, como traços específicos da produção surda, visto que se usavam apenas a soletração do nome oficial em Português, atualmente, passa a ser essencial pensar nas especificidades do sinal-nome das personagens e torna-se uma das tarefas dos tradutores, como discute Albres (2012).

\section{Concluindo. $O$ que aprendemos com as escolhas desses tradutores?}

As formas de introduzir os sinais-nome e os critérios para sua criação revelaram a autoria dos tradutores, conceito este ainda controverso nos estudos da tradução. A posição autoral do tradutor como novo enunciador foi fortemente influenciada pela materialidade linguística (livro de literatura infanto-juvenil congregando elementos verbo-visuais, tanto os do texto e os das ilustrações do livro) quanto elementos extralinguísticos relacionados à sua construção de sentido única, visto sua posição histórico-cultural.

A imagem (ilustração) das personagens constituiu papel fundamental para criação dos sinais-nome das personagens de literatura infanto-juvenil. Enunciados próprios dos tradutores, por vezes, distantes do texto de partida, mas essencialmente deles, constituem o fazer do 90 tradutor na cadeia discursiva. A construção de enunciados na tradução para uma língua gestualvisual requer criações, adaptações e acréscimos tendo como elo o projeto enunciativodiscursivo da obra.

Nesse tecido dialógico, nas palavras do texto de partida (aquilo que se pretendeu dizer no livro impresso) e pela atividade responsiva de contrapalavras do tradutor se constrói uma nova enunciação, marcada por sua subjetividade e história de vida, sua interpretação - única, devendo ir se distanciado do original e procurando se aproximar do público alvo dialeticamente, sento ética e esteticamente atraente.

\section{REFERÊNCIAS BIBLIOGRÁFICAS}

AGUILERA, Elvira Cámara. The translation of Proper Names in Children's Literature. Ef@bulations/e-f@bulações. Disponível

em: <http://ler.letras.up.pt/uploads/ficheiros/4666.pdf>. Acesso em 20 de jan. 2012.

ALBRES, Neiva de Aquino. Tradução de literatura infantil: entre a construção de sentidos e o uso dos recursos linguísticos. In: III Congresso Brasileiro de Pesquisas em Tradução e Interpretação de Língua Brasileira de Sinais e Língua Portuguesa. Florianópolis-SC: UFSC. 15 a 17 de agosto de 2012.

AUBERT, Francis Henrik. As infidelidades da tradução: servidões e autonomia do tradutor. Campinas- SP, editora da Unicamp, 1994. 
Autor desconhecido. A História de Aladim e a lâmpada maravilhosa. Tradução de: Ana Regina Campello e Nelson Pimenta. CD-ROM. Petrópolis/Rio de Janeiro: Arara Azul 2004.

BAKHTIN, Mikhail (Volochínov). Marxismo e Filosofia da Linguagem. São Paulo: Ed. Hucitec, 1992 (publicado originalmente em 1929).

BAKHTIN, Mikhail Mikhailovicht. O autor e a personagem na atividade estética. In: Estética da criação verbal. $5^{\text {a }}$ ed. São Paulo: Editora Martins Fontes, 2010a. p. 3-90. (publicado originalmente em 1923).

BAKHTIN, M. Questões de Literatura e de Estética. 6. ed. Tradução: Aurora Fornoni Bernardini et alii. Campinas: Hucitec Editora, 2010 b.

CAMPOS, Geir. Como fazer tradução. Petrópolis: Vozes, 1986.

COLLODI, Carlo. As aventuras de Pinóquio. Tradução de: Ana Regina Campello e Nelson Pimenta. CD-ROM. Petrópolis/Rio de Janeiro: Arara Azul. 2003.

DAY, Linda; SUTTON-SPENCE, Rachel. British Sign Name Customs. Sign Language Studies. Volume 11, Number 1, Fall 2010.

FREITAS, Cristiane Adélia Morgenroth de. Analise das propriedades articulatórias dos sinais de pessoas. Monografia de Especialização em Libras. Orientação de André Nogueira Xavier. São Paulo: Faculdade de agudos- FAAG, 2011.

FOX, Mem . Guilherme Augusto Araujo Fernandes. Editora Brinque Book. CD-ROM. São Paulo Brinque Book, 2008.

KARNOPP, Lodenir Becker. Produções culturais de surdos: análise da literatura surda. Cadernos de Educação | FaE/PPGE/UFPel | Pelotas [36]: 155 - 174, maio/agosto 2010.

KING, Stephen Michael . O Homem que amava caixas. CD-ROM. São Paulo Brinque Book, 2008.

KOURBETIS, Vassilis; HOFFMEISTER, Robert J. Name Signs in Greek Sign Language. American Annals of the Deaf. Volume 147, Number 3, July 2002. Disponível em: http://muse.jhu.edu/journals/american_annals_of_the_deaf/v147/147.3.kourbetis.html

McKEE, Rachel Locker; McKEE, David. Name Signs and Identity in New Zealand Sign Language. In: METZER, Melaine (org.). Bilingualism \& Identity in Deaf Communities. United States of America: Galaudett University Press, 2000. Disponível em: http://books.google.com.br/books?id=lleapJguEG8C\&printsec $=$ frontcover\&hl=pt-

$\mathrm{BR} \# \mathrm{v}=$ onepage $\& \mathrm{q} \& \mathrm{f}=$ false

MEADOW, Kathryn P. Name Signs as Identity Symbols in the Deaf Community. Sign Language Studies, 16, 237-246, Aut 1977.

MINDESS, Anna. What Name Signs Can Tell Us about Deaf Culture. Sign Language Studies, n66 p1-23 Spr, 1990. 
MORAIS, Carla Damasceno de. Tecido na língua de sinais: B-R-A-N-C-A D-E N-E-V-E E O$S S-E-T-E A-N-\tilde{O}-E-S$. Dissertação de mestrado do Programa de Pós-Graduação em Literatura da Universidade Federal de Santa Catarina, UFSC: 2010.

MOURÃO, Claudio Henrique Nunes. Adaptação e tradução em literatura surda: a produção cultural surda em língua de sinais. In: IX ANPED Sul. Seminário de pesquisa em educação da região Sul. 2012.

NASCIMENTO, Marcus Vinícius Batista. Interpretação da língua brasileira de sinais a partir do gênero jornalístico televisivo: elementos verbo-visuais na produção de sentidos. 2011. 149p. Dissertação (Mestrado em Linguística Aplicada e Estudos da Linguagem - LAEL). PUC-SP, 2011.

Interpretação da libras para o português na modalidade oral: considerações dialógicas. Tradução \& Comunicação: Revista Brasileira de Tradutores. n. ${ }^{\circ}$ 24. p. 79-94, 2012. Disponível em: http://sare.unianhanguera.edu.br/index.php/rtcom/article/view/3733/1368

PAALES, Liina. Name signs for hearing people. Published in the 2009 Yearbook of the Learned Estonian Society. Disponível: 〈http://www.folklore.ee/Folklore/vol47/paales.pdf>

PAALES, Liina. On the System of Person-Denoting Signs in Estonian Sign Language: Estonian Personal Name Signs. Sign Language Studies. Volume 10, Number 3, Spring 2010.

SUPALLA, Samuel J. The Arbitrary Name Sign System in American Sign Language. Sign Language Studies, n67 p99-126 Sum 1990. Disponível:

http://www.eric.ed.gov/ERICWebPortal/search/detailmini.jsp?_nfpb=true\&_\&ERICExtSearc h_SearchValue_0=EJ410404\&ERICExtSearch_SearchType_0=no\&accno=EJ410404

VENUTI, Lawrence. Autoria. In: VENUTI, Lawrence. Escândalos da tradução. Bauru, SP: EDUSC, 2002. pp.65-92.

VYGOTSKY, Lev Semenovich. Problemas de método. In: VYGOTSKI, Lev Semenovich. A Formação Social da Mente. São Paulo: Martins Fontes, 1998.

WILCOX, Sherman, WILCOX, Phyllis Perrin; JARQUE, Maria Josep. Mappings in conceptual space: Metonymy, metaphor, and iconicity in two signed languages. In: Jezikoslovlj e 4.1. 2003 - pp. 139-156.

\footnotetext{
${ }^{\mathrm{i}}$ Neiva de Aquino ALBRES - Professora da Universidade Federal de Santa Catarina. Doutora em Educação Especial pela Universidade Federal de São Carlos (2013). Mestre em Educação pela Universidade Federal de Mato Grosso do Sul (2005). Graduação em Normal Superior pela Universidade Estadual de Mato Grosso do Sul (2003) e em Fonoaudiologia pela Universidade Católica Dom Bosco (1999). Disponível em: http://neivaalbres.paginas.ufsc.br/ e http://lattes.cnpq.br/1652645656634694. Acesso: junho 2016.
}

RECEBIDO EM: 26 de fevereiro de 2016 ACEITO EM: 16 de junho de 2016 